\title{
The Effect of High Loading Rate on the Behaviour and Mechanical Properties of Coal-Rock Combined Body
}

\author{
Fengqiang Gong $\mathbb{D}^{1,2}{ }^{1,2}$ Hao Ye, ${ }^{1}$ and Yong Luo ${ }^{1}{ }^{1}$ \\ ${ }^{1}$ School of Resources and Safety Engineering, Central South University, Changsha, Hunan 410083, China \\ ${ }^{2}$ State Key Laboratory of Coal Resources and Safe Mining, China University of Mining and Technology, Xuzhou, Jiangsu 221008, China \\ Correspondence should be addressed to Fengqiang Gong; fengqiangg@126.com
}

Received 5 January 2018; Accepted 9 May 2018; Published 25 June 2018

Academic Editor: Xinglin Lei

Copyright (c) 2018 Fengqiang Gong et al. This is an open access article distributed under the Creative Commons Attribution License, which permits unrestricted use, distribution, and reproduction in any medium, provided the original work is properly cited.

\begin{abstract}
In order to investigate the high loading rate effect on the behaviour and mechanical properties of coal-rock combined body, the dynamic compressive tests were conducted by using the Split-Hopkinson Pressure Bar (SHPB) device under the loading rate range from $2.7 \times 10^{5} \mathrm{MPa} / \mathrm{s}$ to $4.0 \times 10^{5} \mathrm{MPa} / \mathrm{s}$. The stress-strain curves, dynamic peak stress and strain, elastic modulus, and energy distribution law of coal-rock combined body under different loading rates were analyzed and discussed. The results show that the dynamic stress-strain curves of coal-rock combined body have a double-peak feature under high loading rate range, which can be divided into the initial bearing stage, the bearing decline stage, the bearing enhance stage, and the unstable stage. The first peak stress of the coal-rock combined body is independent of the loading rate, while the dynamic compressive strength (the second peak stress) and dynamic peak strain (the second peak strain) have a strong loading rate effect and will generally increase linearly with the loading rate. The first and second elastic moduli of coal-rock combined body are not sensitive to the loading rate. With the increase of the loading rate, the incident energy and reflective energy of coal-rock combined body increase rapidly, while the change of transmitted energy is very small. The absorption energy ratio of the coal-rock combined body shows a good linear law with the incident energy under different loading rates.
\end{abstract}

\section{Introduction}

In deep mining of coal mine, rock burst or coal burst is often encountered and is becoming more and more serious with the increase of depth, which seriously threatens the safety of mine production [1]. Rock burst is essentially a dynamic failure of coal-rock combined body under the mining disturbance [2-5]. In order to investigate the mechanical properties and failure modes of coal-rock combined body, many researchers have done a lot of experimental researches [6-10]. For example, Zuo et al. [6-8] studied the influence of dip angle, confining pressure, and different stress conditions on the failure characteristics of coal-rock combined body. Huang et al. [9] and Gong et al. [10] analyzed the effect of low loading rate on the mechanical behaviour of coal-rock combined body. In the above researches, the mechanical response of coal-rock combined body in quasi-static range was mainly studied. However, in the process of excavation, the coal-rock combined body will inevitably be influenced by the dynamic disturbances (such as mechanical shock, blasting load, etc.), and it is also necessary to study the strength and deformation characteristics of coal-rock combined body under high loading rate. In addition, the experimental research on coal-rock combined body under high loading rate was relatively few. In this paper, the dynamic compressive tests were conducted by using a Split-Hopkinson Pressure Bar (SHPB) device under the loading rate range from $2.7 \times 10^{5} \mathrm{MPa} / \mathrm{s}$ to $4.0 \times 10^{5} \mathrm{MPa} / \mathrm{s}$, and the strength characteristics, failure modes, and energy distribution law of coal-rock combined body were obtained and analyzed.

\section{Specimen Preparation and Testing Methodology}

2.1. Specimen Preparation. Referring to literature [11], the specimen of coal-rock combined body was designed into a cylinder with a diameter of $50 \mathrm{~mm}$ and height of $50 \mathrm{~mm}$. 


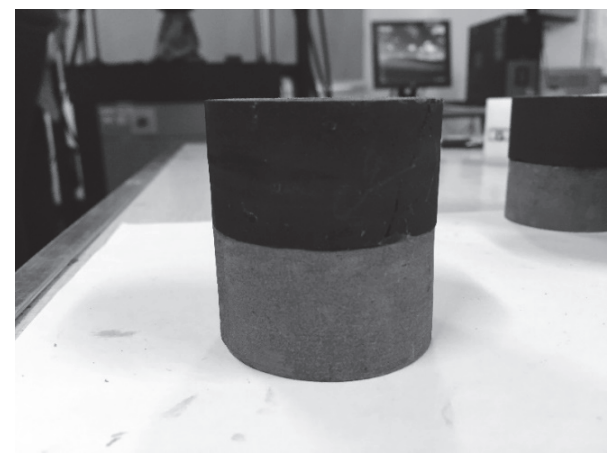

FIGURE 1: Specimen photograph of coal-rock combined body.
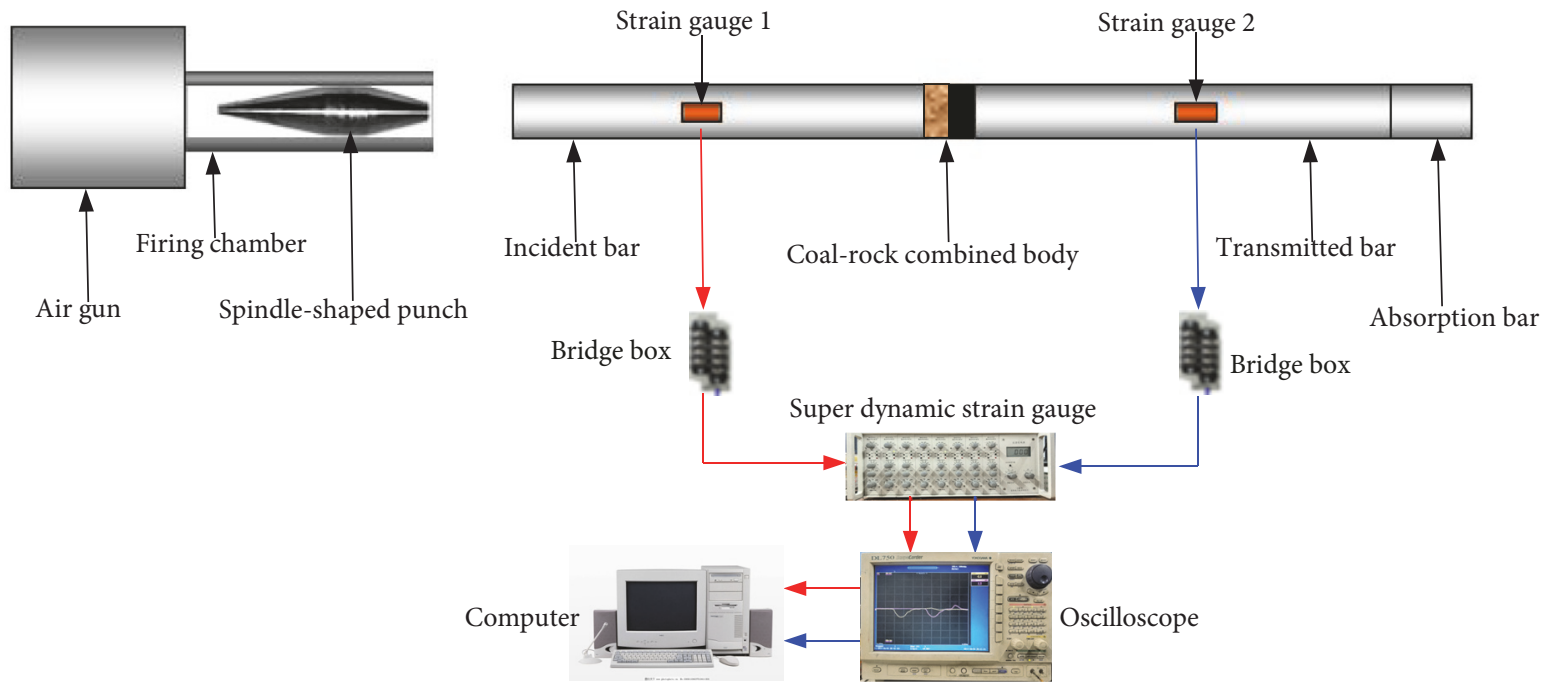

FIGURE 2: Experimental system sketch of SHPB apparatus.

The coal block and rock block were taken from Zhaogu 2\# mine of Jiaozuo mining area, China. The average compressive strength and elastic modulus of coal are $16.2 \mathrm{MPa}$ and $3.22 \mathrm{GPa}$, and those of sandstone are $95.4 \mathrm{MPa}$ and 16.8 GPa. Moreover, the densities of coal and sandstone are $1371.4 \mathrm{~kg} / \mathrm{m}^{3}$ and $2301.2 \mathrm{~kg} / \mathrm{m}^{3}$, respectively. Both the coal sample and rock sample were processed into a cylinder of $50 * 25 \mathrm{~mm}$ firstly. In order to get the complete coal-rock combined body specimen, the adhesive was used to bond the coal sample and the rock sample together subsequently. In the existing literature, there are a variety of adhesives used in the manufacture of coal-rock combined body specimen, such as the super glue [9], the latex adhesive [11, 12], the strong adhesive [13], the 502 glue [14], and the AB adhesive [15]. Based on the consideration of the properties of above adhesives and to satisfy the requirements of experimental precision, a kind of modified acrylate adhesive with small colloid volume, whose property is similar to that of the strong adhesive or $\mathrm{AB}$ adhesive, was adopted to bond the coal sample and rock sample. A representative wellprocessed coal-rock combined body specimen is shown in Figure 1.
2.2. Test Equipment and Testing Methodology. In the investigation of the dynamic characteristics of rock or coal materials under high loading rate [16-19], the Split-Hopkinson Pressure Bar (SHPB) has been used widely and also adopted in the dynamic compression tests of coal-rock combined body in this paper (Figure 2). As shown in Figure 2, in order to eliminate wave oscillation and reduce wave dispersion effects, the half-sine incident stress wave generated with a spindle-shaped striker has been suggested as the ideal loading waveform for SHPB device [20]. Before the dynamic tests, the coal-rock combined body specimen was sandwiched between the incident bar and the transmitted bar, and the stress wave transfer is made from the rock sample to the coal sample in the combined body specimen to simulate the actual stressed state of coal-rock strata under impact loading. After the impact loading, the incident and reflective signals can be recorded by strain gauge 1 , and the transmitted signal was also recorded by strain gauge 2 (Figure 3 ).

Before the tests, the basic geometric and physical parameters of coal-rock combined body were measured (Table 1). The nitrogen valve was used to adjust the impact pressure and to achieve different levels of incident energy. Three impact 


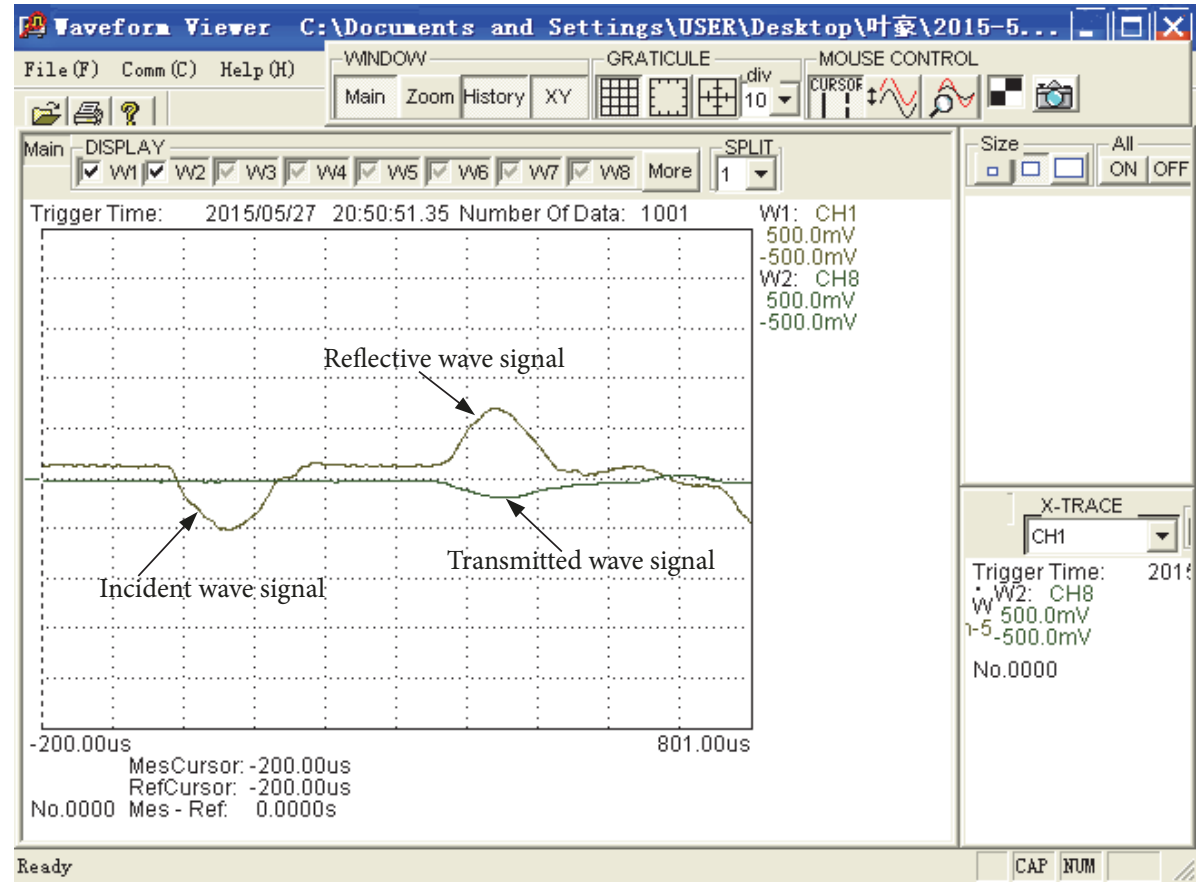

FIGURE 3: Incident wave, reflective wave, and transmitted waves recorded during the impact test.

TABLE 1: Testing results of coal-rock combined body.

\begin{tabular}{cccccc}
\hline No. & $\begin{array}{c}D \\
(\mathrm{~mm})\end{array}$ & $\begin{array}{c}L \\
(\mathrm{~mm})\end{array}$ & $\begin{array}{c}\rho_{m r} \\
\left(\mathrm{~kg} / \mathrm{m}^{3}\right)\end{array}$ & $\begin{array}{c}v \\
(\mathrm{~km} / \mathrm{s})\end{array}$ & $\begin{array}{c}\text { Impact pressure } \\
(\mathrm{MPa})\end{array}$ \\
\hline A1 & 48.0 & 51.2 & 1886.2 & 2.1 & 0.5 \\
A2 & 48.1 & 50.9 & 1909.0 & 1.8 & 0.5 \\
A3 & 48.0 & 52.4 & 1862.2 & 2.4 & 0.6 \\
A4 & 48.0 & 51.3 & 1852.9 & 2.0 & 0.6 \\
A6 & 48.0 & 52.2 & 1871.4 & 2.1 & 0.7 \\
A7 & 48.1 & 52.4 & 1901.1 & 1.9 & 0.7 \\
\hline
\end{tabular}

Note. $D$ : diameter of combined body; $L$ : thickness of combined body; $\rho_{m r}$ : total density of combined body; $v$ : longitudinal wave velocity of combined body.

pressures of $0.5,0.6$, and $0.7 \mathrm{MPa}$ were set separately and two specimens were tested at each impact pressure. Both the ends of specimen were evenly coated with Vaseline to reduce the influence caused by the end-face friction.

During the SHPB tests, stress equilibrium at both ends of the specimen is the necessary condition to ensure the accuracy of the test results. Figure 4 shows the results of stress equilibrium check for the dynamic compression tests of coalrock combined body. It can be seen that the stresses on both ends of the coal-rock combined body specimen are very close, which indicates that the specimen will be in a state of stress equilibrium during the dynamic loading process.

\section{Dynamic Compressive Test Results and Discussions}

According to the principle of one-dimensional stress wave propagation during SHPB test, the stress-strain curves of

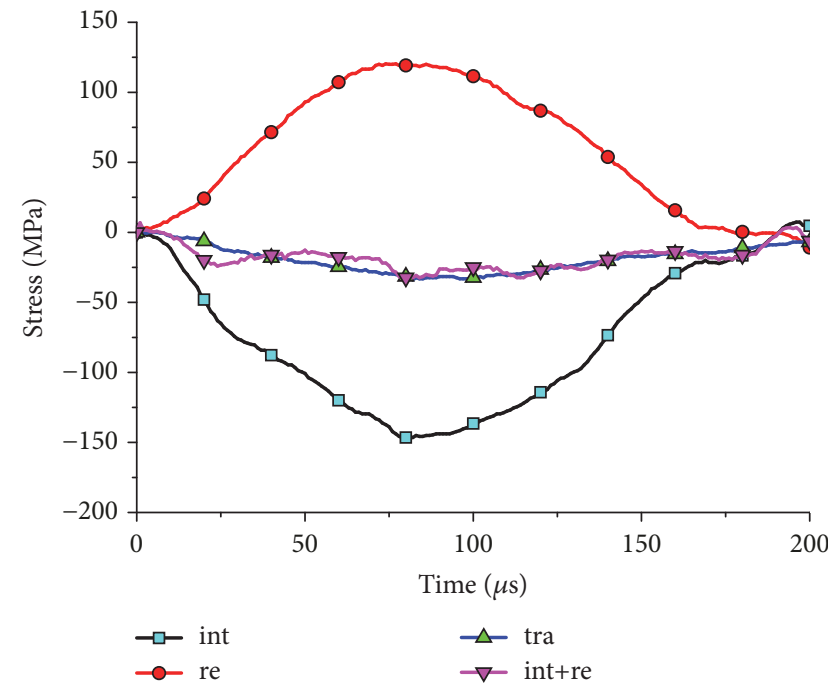

Figure 4: Stress equilibrium check for the dynamic compression tests of coal-rock combined body.

coal-rock combined body can be obtained. The results of the loading rate, stain rate, peak stress, elastic modulus, and energy consumption parameters are also calculated (Table 2).

3.1. The Corresponding Relation of Rate Effect Parameters. In dynamic tests, both loading rate and strain rate are usually used as the rate effect parameters. However, the corresponding relation between the two parameters was rarely investigated. The previous studies show that there is a linear function relationship between the logarithm of loading 
TABLE 2: Test results of dynamic compressive tests of coal-rock combined body.

\begin{tabular}{|c|c|c|c|c|c|c|c|c|c|c|}
\hline No. & $\begin{array}{c}\dot{\sigma} \\
(\mathrm{MPa} / \mathrm{s})\end{array}$ & $\begin{array}{c}\dot{\varepsilon} \\
\left(\mathrm{s}^{-1}\right)\end{array}$ & $\begin{array}{c}\sigma_{1} \\
(\mathrm{MPa})\end{array}$ & $\begin{array}{c}\sigma_{2} \\
(\mathrm{MPa})\end{array}$ & $\begin{array}{c}E_{1} \\
(\mathrm{GPa})\end{array}$ & $\begin{array}{c}E_{2} \\
(\mathrm{GPa})\end{array}$ & $\begin{array}{l}E_{I} \\
(J)\end{array}$ & $\begin{array}{l}E_{R} \\
(\mathrm{~J}) \\
\end{array}$ & $\begin{array}{c}E_{T} \\
(\mathrm{~J}) \\
\end{array}$ & $\begin{array}{r}E_{A} \\
(J) \\
\end{array}$ \\
\hline A1 & $2.71 \times 10^{5}$ & 65.90 & 11.06 & 28.23 & 7.5 & 2.2 & 55.67 & 37.54 & 2.89 & 15.23 \\
\hline $\mathrm{A} 2$ & $2.74 \times 10^{5}$ & 70.25 & 9.51 & 34.43 & 8.2 & 2.3 & 52.02 & 34.83 & 6.75 & 10.44 \\
\hline A3 & $2.98 \times 10^{5}$ & 65.90 & 9.36 & 37.23 & 6.8 & 2.7 & 60.49 & 40.02 & 3.87 & 16.58 \\
\hline $\mathrm{A} 4$ & $3.36 \times 10^{5}$ & 77.07 & 9.43 & 41.32 & 8.5 & 2.6 & 79.81 & 56.91 & 6.22 & 16.67 \\
\hline A6 & $3.41 \times 10^{5}$ & 80.14 & 10.63 & 43.36 & 7.5 & 2.8 & 88.15 & 58.93 & 5.85 & 23.35 \\
\hline A7 & $4.01 \times 10^{5}$ & 92.12 & 10.20 & 44.49 & 8.0 & 2.8 & 107.42 & 74.38 & 6.00 & 27.03 \\
\hline
\end{tabular}

Note. $\dot{\sigma}$ : loading rate; $\dot{\varepsilon}$ : strain rate; $\sigma_{1}$ : the first peak stress; $\sigma_{2}$ : the second peak stress; $E_{A}$ : absorption energy; $E_{1}$ : the first elastic modulus before the first peak stress; $E_{2}$ : the second elastic modulus before the second peak stress; $E_{I}$ : incident energy; $E_{R}$ : reflective energy; $E_{T}$ : transmitted energy.

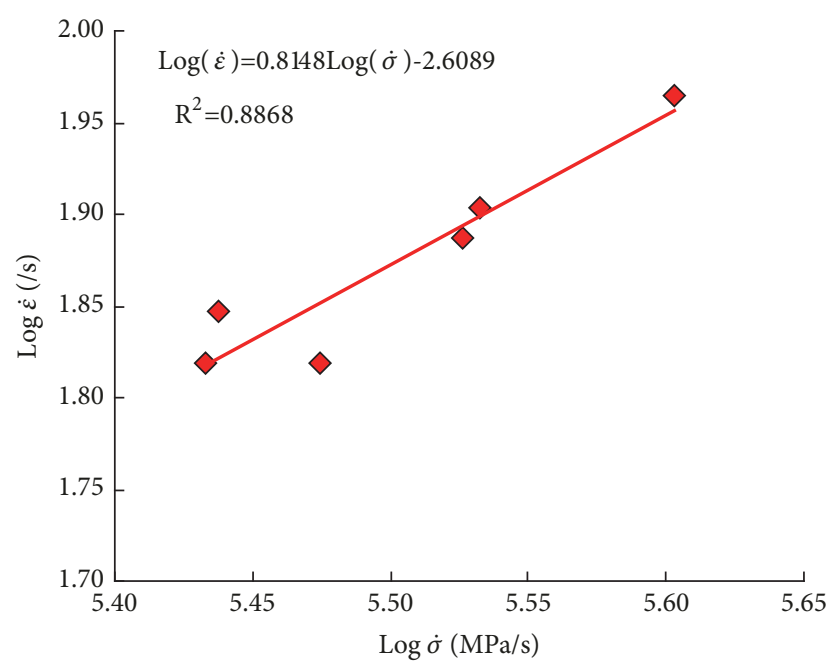

FIGURE 5: Relationship between the logarithm of loading rate and the logarithm of strain rate.

rate and the logarithm of strain rate under low loading rate range [10]. Under high loading rate range of this paper, the relationship between the logarithm of loading rate and the logarithm of strain rate can also be expressed as linear function as follows (Figure 5):

$$
\log (\dot{\varepsilon})=k \log (\dot{\sigma})+c
$$

where $k$ and $c$ are fitting coefficients.

3.2. The Failure Mode of Coal-Rock Combined Body Specimen. The failure modes of the coal-rock combined body specimen at different loading rate are shown in Figure 6. It can be seen that there is a great difference between the failure modes of coal samples and rock samples in the coal-rock combined body specimen. The coal samples were broken into small pieces, while all rock samples have relatively large failure blocks under different loading rates, which show that the bearing capacity of rock samples was greater than that of coal samples. With the increase of the loading rate, the broken blocks of rock sample are getting smaller and smaller. When the loading rate is less than $3.00 \times 10^{5} \mathrm{MPa} / \mathrm{s}$, rock samples were generally broken into $2-3$ blocks. When the loading rate is greater than $3.00 \times 10^{5} \mathrm{MPa} / \mathrm{s}$, the number of broken blocks of rock samples is 6-8. The above results show that with the increase of the loading rate, the external energy applied to coal-rock combined body is getting higher and higher, and the damage degree of coal-rock combined body is becoming more and more serious.

3.3. The Stress-Strain Curves of Coal-Rock Combined Body. The stress-strain curves of coal-rock combined body specimens under high loading rate are shown in Figures 7 and 8. It can be seen that all the stress-strain curves have a two-peak feature on the whole. The stress-strain curve can be divided into four stages, that is, the initial bearing stage I $(a b)$, the bearing decline stage II $(b c)$, the bearing enhance stage III $(c d)$, and the unstable stage IV (de) (Figure 7(a)).

The reason why there are two peak stresses in the stress-strain curve of combined specimen is closely related to the propagation of stress waves in coal body and rock body. During the loading process, the stress wave was first introduced into the sandstone from the incident bar. Owing to fast wave velocity and higher strength of sandstone, the sandstone sample remains stable at the initial stage of loading. When the stress wave is approximately transmitted to the rock-coal body interface, a local failure occurs in the coal sample because of its low velocity and weaker strength. Thus, the first peak stress was formed in the early stage of loading. However, with the transmission of stress wave, the coal sample still possesses certain bearing capacity that enables it to be compacted together with the rock sample and continues to bear the dynamic load until the rock sample also breaks up, then forming the second peak stress.

3.4. Strength and Deformation Characteristics of Coal-Rock Combined Body. To more systematically investigate the strength and deformation characteristics of coal-rock combined body under different high loading rates, the maximum stress (the second peak stress) was defined as the dynamic compressive strength of coal-rock combined body and the corresponding strain (the second peak strain) is the dynamic peak strain. As shown in Figure 9(a), the dynamic compressive strength of coal-rock combined body increases with the loading rate, which exhibits a strong rate effect on the strength 


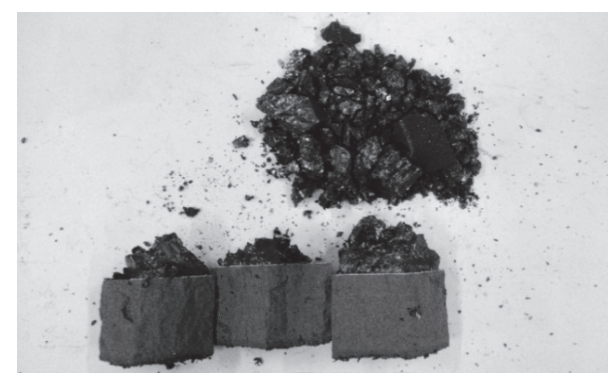

(a) $\mathrm{Al}: 2.71 \times 10^{5} \mathrm{MPa} / \mathrm{s}$

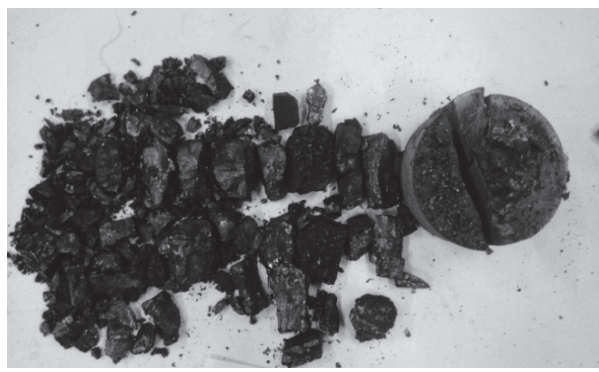

(c) A3: $2.98 \times 10^{5} \mathrm{MPa} / \mathrm{s}$

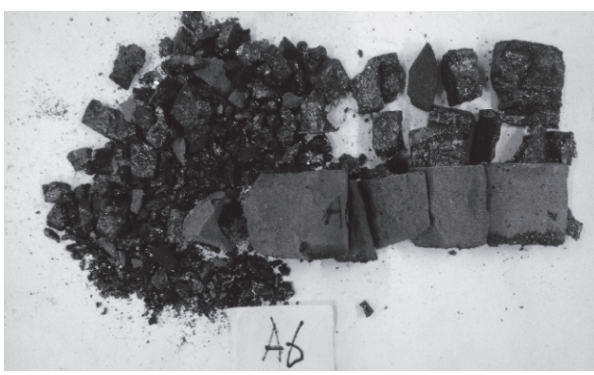

(e) $\mathrm{A} 6: 3.41 \times 10^{5} \mathrm{MPa} / \mathrm{s}$

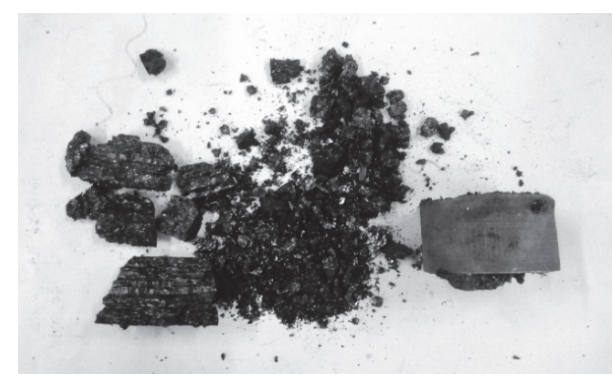

(b) A2: $2.74 \times 10^{5} \mathrm{MPa} / \mathrm{s}$

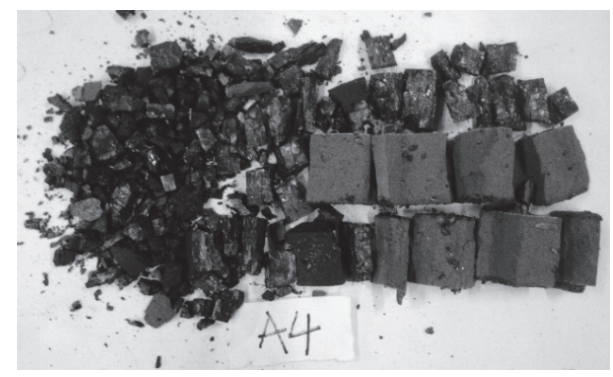

(d) A4: $3.36 \times 10^{5} \mathrm{MPa} / \mathrm{s}$

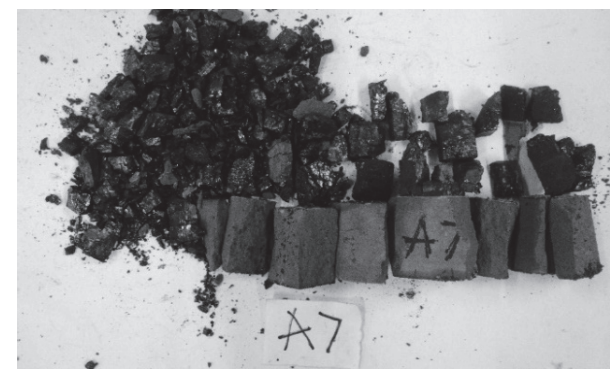

(f) $\mathrm{A} 7: 4.01 \times 10^{5} \mathrm{MPa} / \mathrm{s}$

FIgURE 6: Failure modes of coal-rock combined body specimen.

of coal-rock combined body. And as illustrated in Figure 9(b), the dynamic peak strain of coal-rock combined body also shows a good positive linear relationship with the loading rate.

The stress values of the first peak in the stress-strain curves of all specimens were also measured. As shown in Figure 10, the first peak stress of coal-rock combined body is not sensitive to the increase of loading rate. Compared to Figures 9 and 10, it is concluded that the loading rate mainly affects the second peak strength of coal-rock combined body.

Due to the double-peak characteristic in stress-strain curves, the elastic modulus of coal-rock combined body cannot be calculated with the conventional method. The first and second elastic moduli $E_{1}$ and $E_{2}$ can be obtained, respectively, in the initial bearing stage $I$ and the bearing enhance stage III (Figure 11). From Figure 11, it can be seen that both the first and second elastic moduli are insensitive to loading rate, and the first modulus is always greater than second modulus. Comparing Figures 9, 10, and 11, it can be inferred that the loading rate mainly affects the dynamic compressive strength and strain of coal-rock combined body and does not change the ability of coal-rock combined body to resist deformation.

3.5. Energy Characteristics of Coal-Rock Combined Body. According to the one-dimensional stress wave propagation theory in SHPB test, the incident energy $E_{I}$, reflective energy $E_{R}$, and transmitted energy $E_{T}$ during the dynamic loading process can be expressed as

$$
\begin{aligned}
& E_{I}=\frac{A_{e}}{\rho_{e} C_{e}} \int_{0}^{\tau} \sigma_{I}^{2}(t) d t \\
& E_{R}=\frac{A_{e}}{\rho_{e} C_{e}} \int_{0}^{\tau} \sigma_{R}^{2}(t) d t \\
& E_{T}=\frac{A_{e}}{\rho_{e} C_{e}} \int_{0}^{\tau} \sigma_{T}^{2}(t) d t
\end{aligned}
$$

where $\sigma_{I}(t), \sigma_{R}(t)$, and $\sigma_{T}(t)$ are the incident stress, reflective stress, and transmitted stress correspondingto the time $t$, 


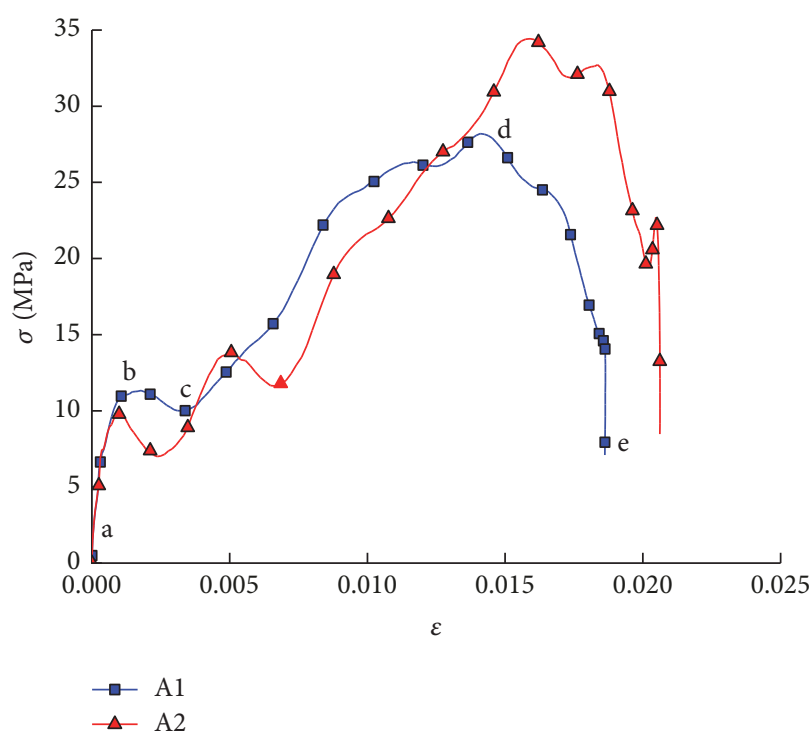

(a) Impact pressure of $0.5 \mathrm{MPa}$

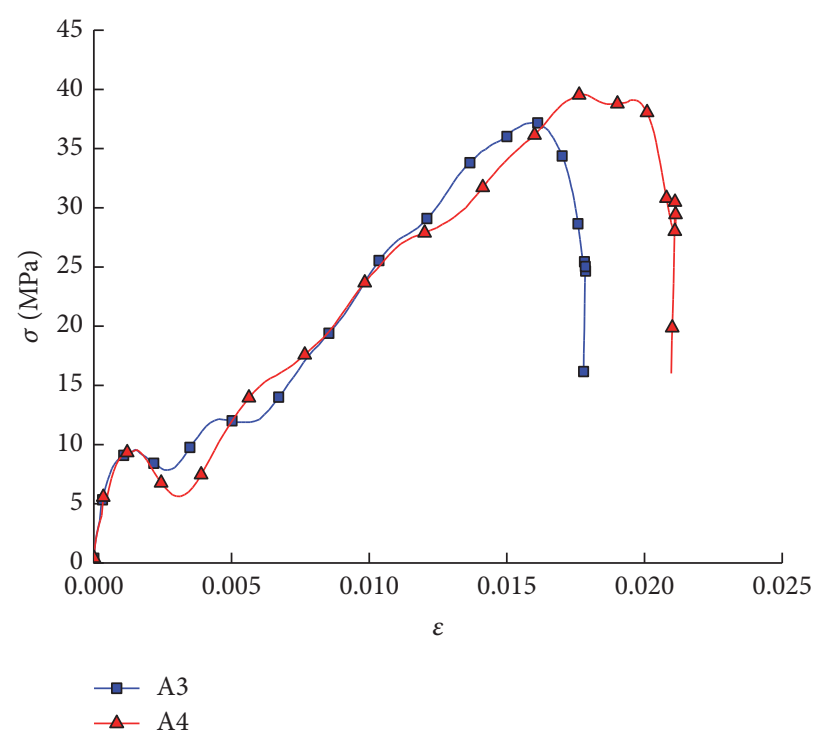

(b) Impact pressure of $0.6 \mathrm{MPa}$

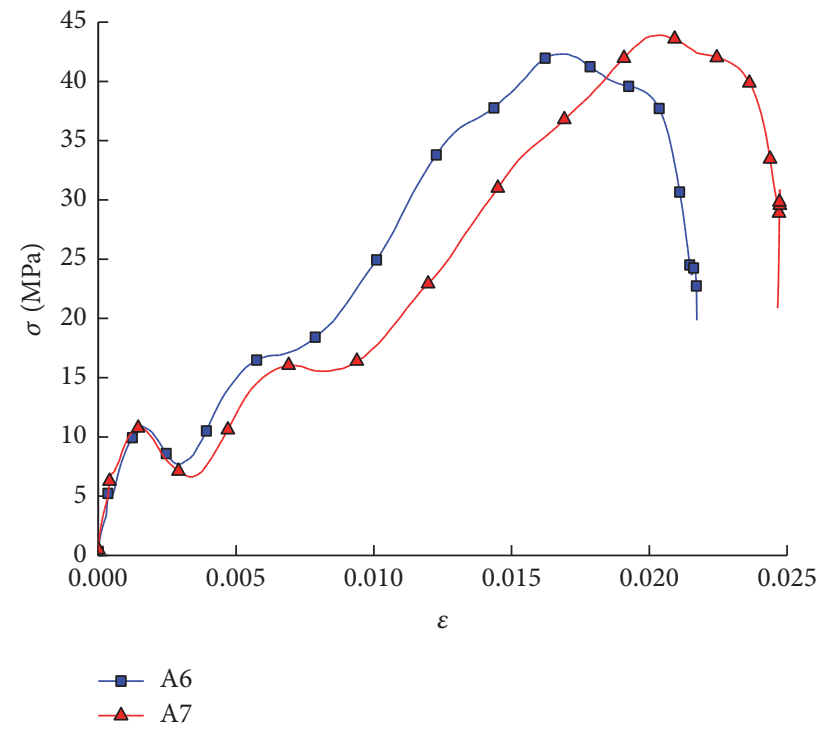

(c) Impact pressure of $0.7 \mathrm{MPa}$

FIGURE 7: Stress-strain curves of coal-rock combined body specimens.

respectively; $\rho_{e} C_{e}$ and $\rho_{s} C_{s}$ are wave impedances of the elastic bar and specimen, respectively. The incident energy, reflective energy, and transmitted energy of coal-rock combined body specimen under different loading rates are shown in Figure 12 . With the increase of the loading rate, the rate effect of the incident energy and reflective energy of coalrock combined body is particularly obvious, and transmitted energy is insensitive to rate effect.

In the analysis of energy consumption law, the absorption energy can directly reflect the energy consumption of coalrock combined body specimen and is given by

$$
E_{A}=E_{I}-E_{R}-E_{T}
$$

Further, the unit volume absorption energy $E_{v}$ can reflect the material absorptive capacity of coal-rock combined body and is calculated by

$$
E_{v}=\frac{E_{A}}{V}
$$

where $\mathrm{V}$ is the total volume of specimen.

As shown in Figure 13, the unit volume absorption energy $E_{v}$ of coal-rock combined body will increase linearly with the increase of the loading rate, which shows that the increase of the loading rate will make the combined body specimen absorb more energy, and the specimen will be more broken after the impact of the high loading rate.

\section{Conclusions}

By using SHPB testing system, the dynamic compression tests of coal-rock combined body were carried out under different high loading rates. Before the test, the stress equilibrium at 


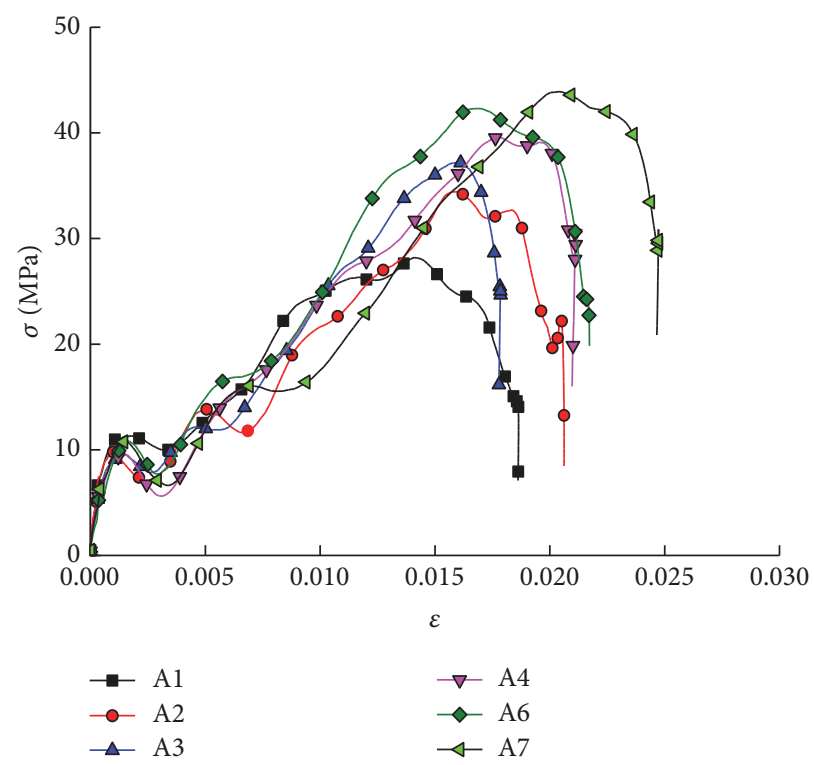

FIGURE 8: Stress-strain curves of coal-rock combined bodies under different loading rates.

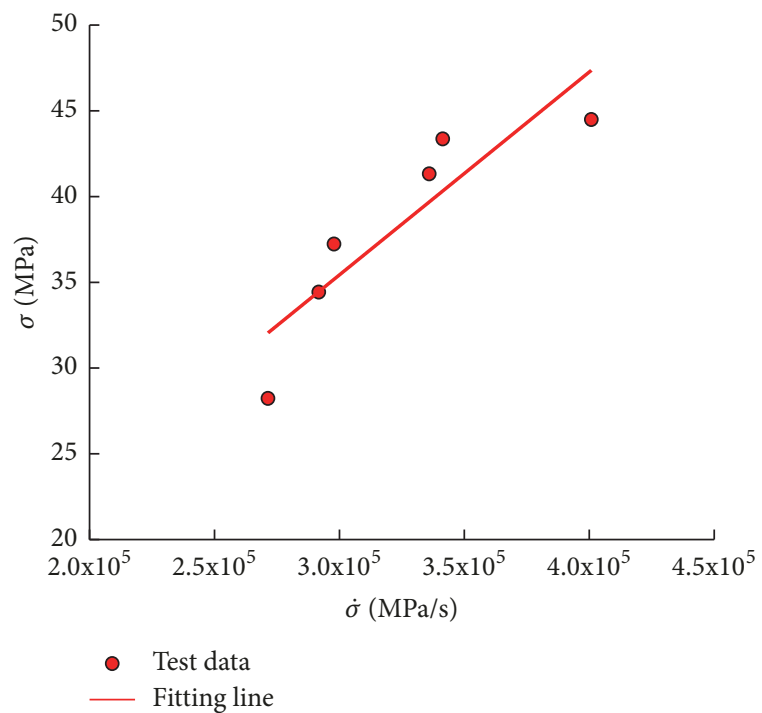

(a) Dynamic compressive strength

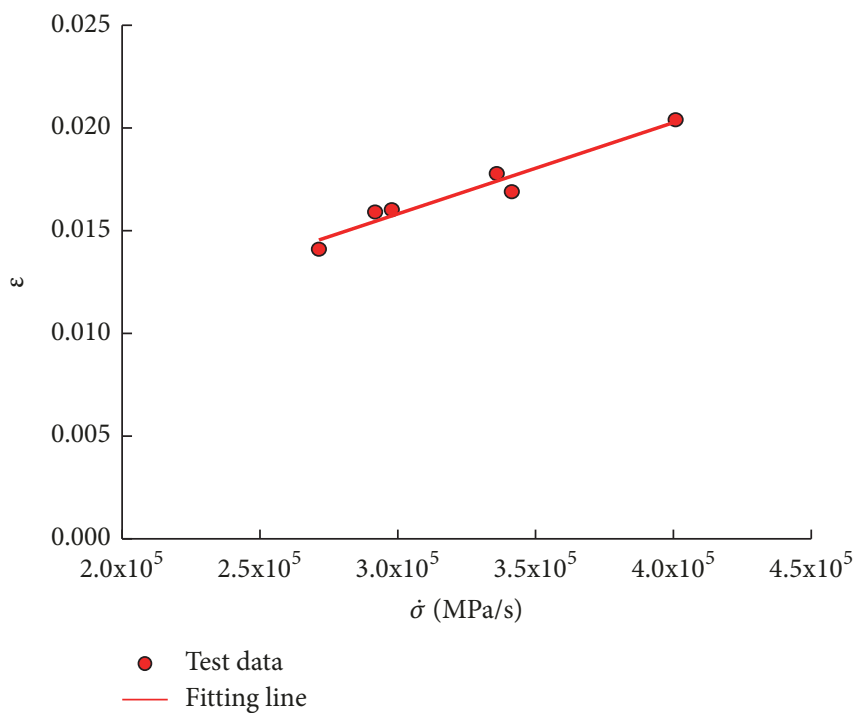

(b) Dynamic peak strain

FIGURE 9: The relationship between dynamic compressive strength, dynamic peak strain, and loading rate.

both ends of coal-rock combined body specimen has been checked, and the results show that the specimens can achieve stress equilibrium during the impact process. 3 kinds of air pressure were set for impact, and the stress-strain curves under 6 loading rates were obtained. The characteristics of failure mode, strength and deformation, and energy distribution law of coal-rock combined body specimens were analyzed. The main conclusions are as follows.

(1) The stress-strain curves of the coal-rock combined body can be divided into four stages: the initial bearing stage, the bearing decline stage, the bearing enhance stage, and the unstable stage.
(2) The stress-strain curves of coal-rock combined body have double-peak feature under high loading rate. The second peak stress is defined as the dynamic compressive strength of coal-rock combined body specimen and will increase with the increase of the loading rate. The first peak stress has no loading rate effect. Both the first and second elastic moduli of coal-rock combined body are independent of the loading rate.

(3) With the increase of the loading rate, the incident energy and reflective energy of coal-rock combined body will increase linearly, while the transmitted energy has little change. Both the unit volume absorption energy and 


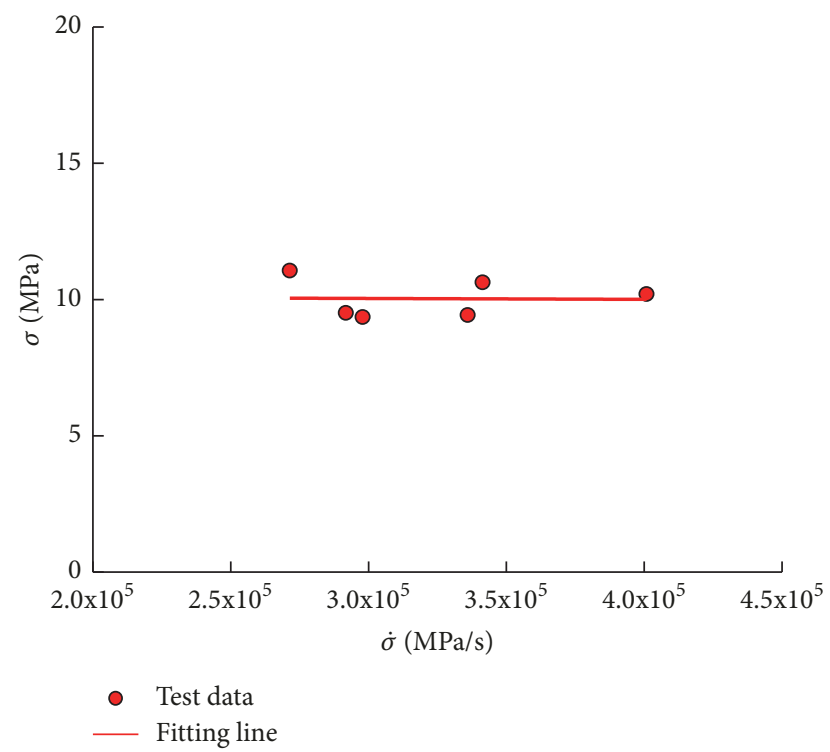

FIGURE 10: The relationship between the first peak stress and loading rate.

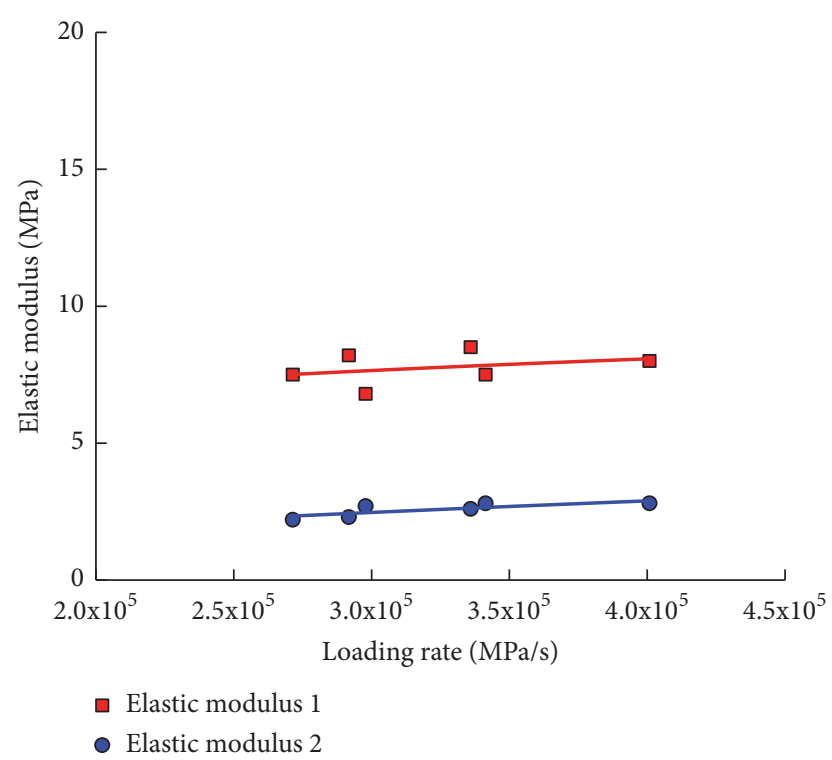

FIGURE 11: Comparison of two elastic moduli under different loading rates.

breaking degree of coal-rock combined body specimen will increase obviously when the loading rate increases.

\section{Data Availability}

The data used to support the findings of this study are available from the corresponding author upon request.

\section{Conflicts of Interest}

The authors declare that they have no conflicts of interest.

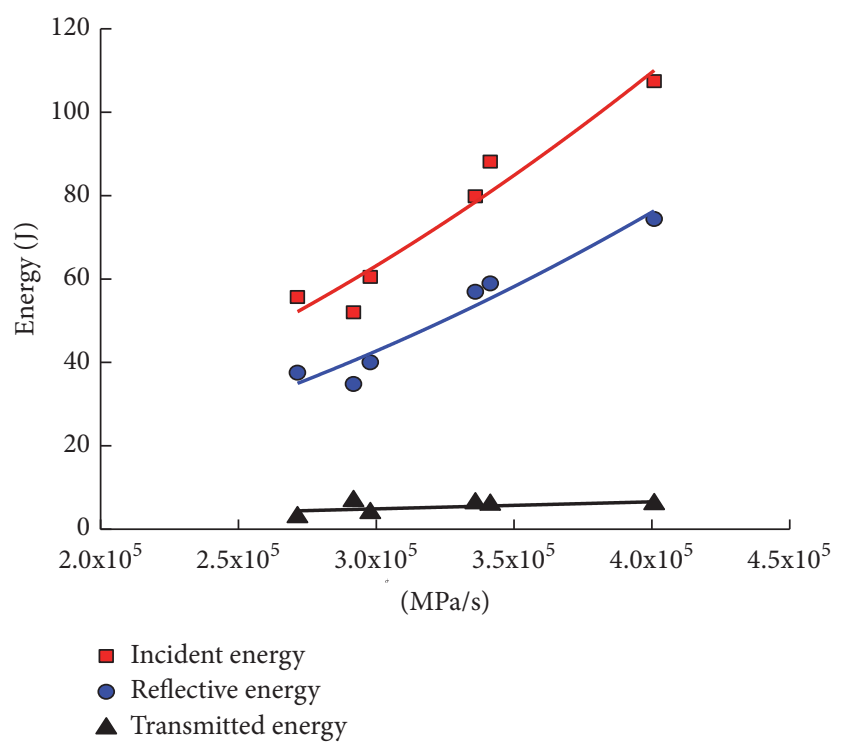

FIGURE 12: Variation in incidence energy, reflective energy, transmitted energy, and loading rate.

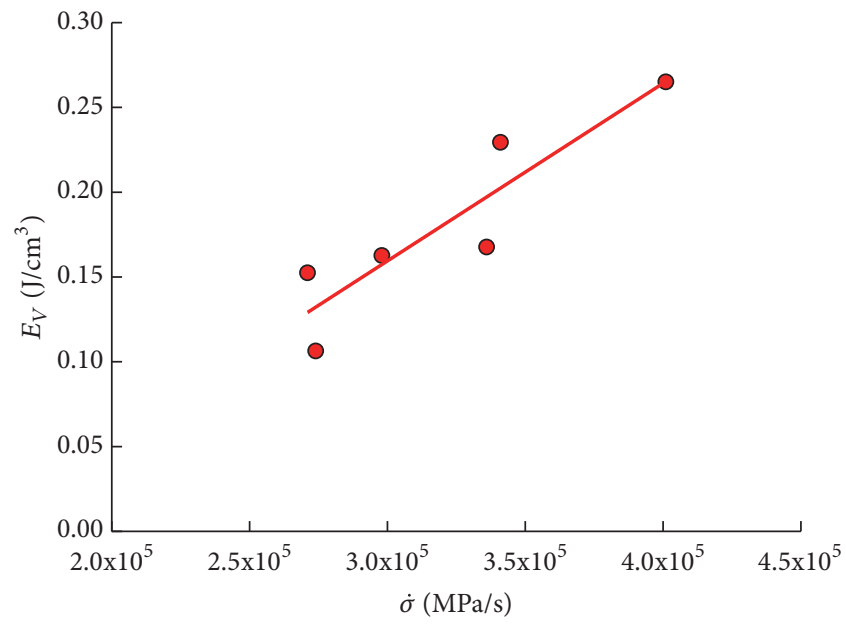

FIGURE 13: Unit volume absorption energy under different loading rates.

\section{Acknowledgments}

This research was financially supported by the Research Project of State Key Laboratory of Coal Resources and Safe Mining, CUMT (13KF06).

\section{References}

[1] H. Xie, F. Gao, and Y. Ju, "Research and development of rock mechanics in deep ground engineering," Chinese Journal of Rock Mechanics and Engineering, vol. 34, no. 11, pp. 2161-2178, 2015.

[2] C. Mark and M. Gauna, "Evaluating the risk of coal bursts in underground coal mines," International Journal of Mining Science and Technology, vol. 26, no. 1, pp. 47-52, 2016.

[3] W. Y. Guo, T. B. Zhao, Y. L. Tan, F. H. Yu, S. C. Hu, and F. Q. Yang, "Progressive mitigation method of rock bursts 
under complicated geological conditions," International Journal of Rock Mechanics \& Mining Science \& Geomechanics, vol. 96, pp. 11-22, 2017.

[4] X. Li, F. Pan, H. Li, M. Zhao, L. Ding, and W. Zhang, "Prediction of rock-burst-threatened areas in an island coal face and its prevention: A case study," International Journal of Mining Science and Technology, vol. 26, no. 6, pp. 1125-1133, 2016.

[5] J. Li, J. Yue, Y. Yang, X. Zhan, and L. Zhao, "Multi-Resolution Feature Fusion model for coal rock burst hazard recognition based on Acoustic Emission data," Measurement, vol. 100, pp. 329-336, 2017.

[6] J. P. Zuo, H. P. Xie, A. M. Wu, and J. Liu, "Investigation on failure mechanisms and mechanical behaviors of deep coal-rock single body and combined body," Chinese Journal of Rock Mechanics and Engineering, vol. 30, no. 1, pp. 84-92, 2011.

[7] J. Zuo, Z. Wang, H. Zhou, J. Pei, and J. Liu, "Failure behavior of a rock-coal-rock combined body with a weak coal interlayer," International Journal of Mining Science and Technology, vol. 23, no. 6, pp. 907-912, 2013.

[8] J.-P. Zuo, Y. Chen, J.-W. Zhang, J.-T. Wang, Y.-J. Sun, and G.-H. Jiang, "Failure behavior and strength characteristics of coal-rock combined body under different confining pressures," Journal of the China Coal Society, vol. 41, no. 11, pp. 2706-2713, 2016.

[9] B. Huang and J. Liu, "The effect of loading rate on the behavior of samples composed of coal and rock," International Journal of Rock Mechanics \& Mining Science \& Geomechanics, vol. 61, pp. 23-30, 2013.

[10] F. Q. Gong, H. Ye, and Y. Luo, "Rate effect on the burst tendency of coal-rock combined body under low loading rate range," Journal of China Coal Society, vol. 42, no. 11, pp. 2852-2860, 2017.

[11] S. H. Liu, D. B. Mao, Q. X. Qi, and F. M. Li, "Under static loading stress wave propagation mechanism and energy dissipation in compound coal-rock," Journal of China Coal Society, vol. 39, pp. 15-22, 2014.

[12] S. Liu, Z. Qin, and J. Lou, "Experimental study of dynamic failure characteristics of coal-rock compound under onedimensional static and dynamic loads," Chinese Journal of Rock Mechanics and Engineering, vol. 33, no. 10, pp. 2064-2075, 2014.

[13] J.-Q. Li, Q.-X. Qi, D.-B. Mao, and Y.-X. Wang, "Discussion on evaluation method of bursting liability with composite model of coal and rock," Chinese Journal of Rock Mechanics and Engineering, vol. 24, no. S1, pp. 4805-4810, 2005.

[14] L. Dou, C. Lu, and Z. Mu, "Rock burst tendency of coal-rock combinations sample," Journal of Mining and Safety Engineering, vol. 23, no. 1, pp. 43-46, 2006.

[15] B. Liu, R. Yang, D. Guo, and D. Zhang, "Burst-prone experiments of coal-rock combination at- $1100 \mathrm{~m}$ level in Suncun coal mine," Chinese Journal of Rock Mechanics and Engineering, vol. 23, no. 14, pp. 2402-2408, 2004.

[16] X. B. Li, T. S. Lok, and J. Zhao, "Dynamic characteristics of granite subjected to intermediate loading rate," Rock Mechanics and Rock Engineering, vol. 38, no. 1, pp. 21-39, 2005.

[17] Q. B. Zhang and J. Zhao, "A review of dynamic experimental techniques and mechanical behaviour of rock materials," Rock Mechanics and Rock Engineering, vol. 47, no. 4, pp. 1411-1478, 2014.

[18] Y. Zhao, G.-F. Zhao, Y. Jiang, D. Elsworth, and Y. Huang, "Effects of bedding on the dynamic indirect tensile strength of coal: Laboratory experiments and numerical simulation," International Journal of Coal Geology, vol. 132, pp. 81-93, 2014.
[19] Y. Zhao, G.-F. Zhao, and Y. Jiang, "Experimental and numerical modelling investigation on fracturing in coal under impact loads," International Journal of Fracture, vol. 183, no. 1, pp. 6380, 2013.

[20] Y. X. Zhou, K. Xia, X. B. Li et al., "Suggested methods for determining the dynamic strength parameters and mode-I fracture toughness of rock materials," International Journal of Rock Mechanics and Mining Sciences, vol. 49, no. 1, pp. 105-112, 2012. 


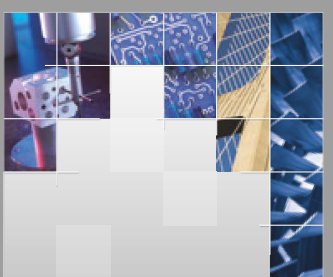

\section{Enfincering}
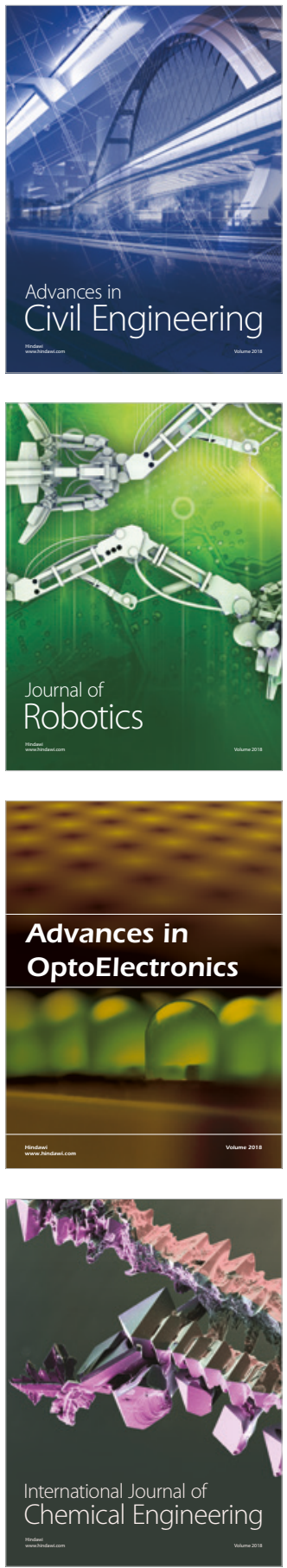

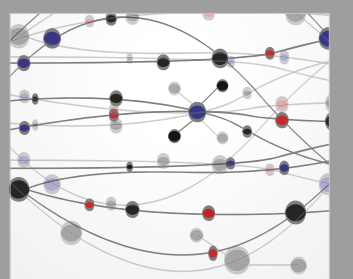

\section{Rotating \\ Machinery}

The Scientific World Journal

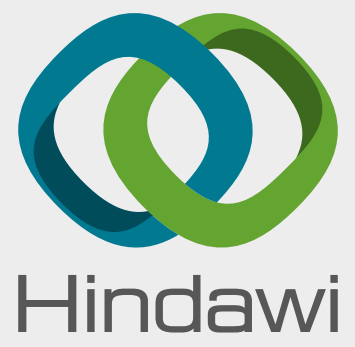

Submit your manuscripts at

www.hindawi.com
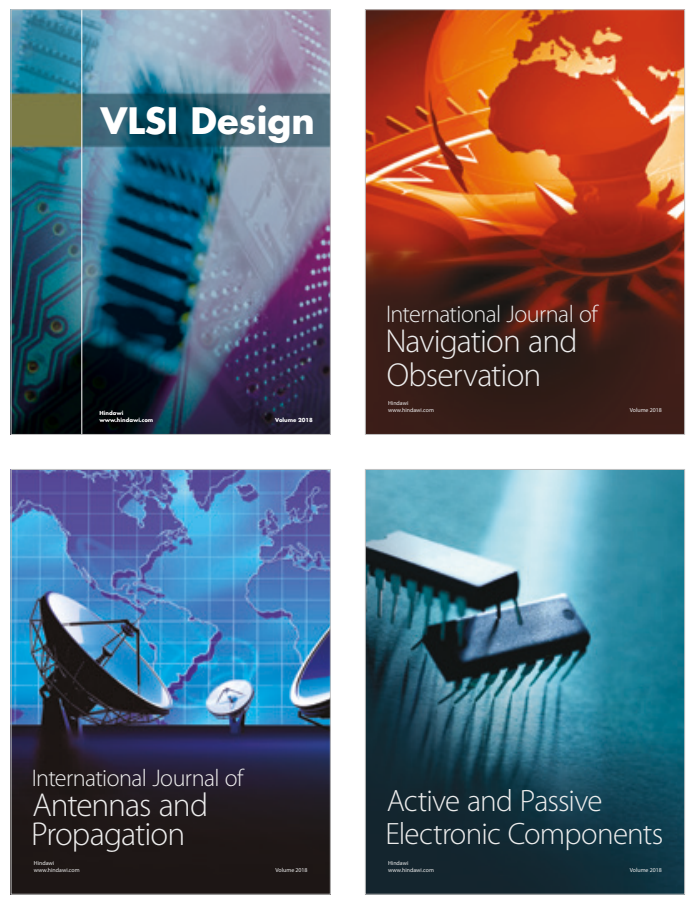
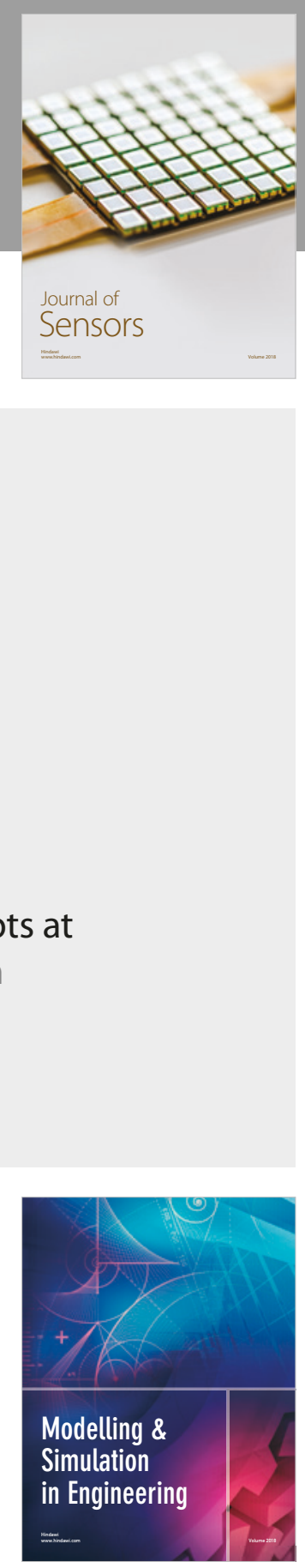

\section{Advances \\ Multimedia}
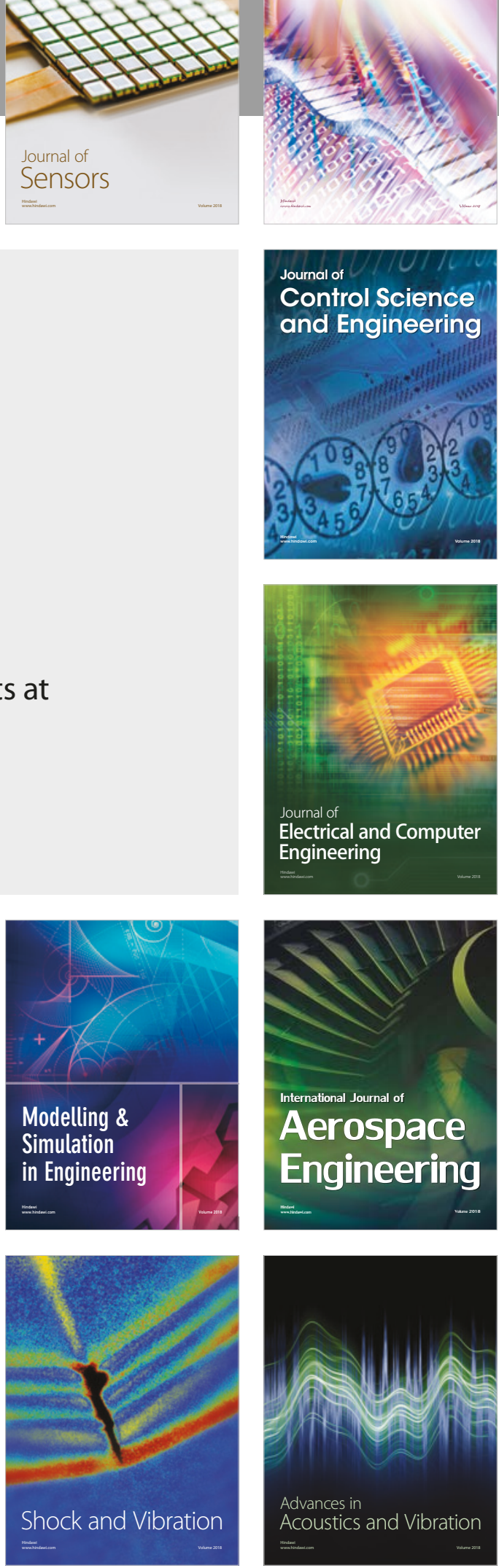